\section{REFLEXIONES ETNOGRÁFICAS SOBRE LA "CIUDADANÍA TRANSNACIONAL". PRÁCTICAS POLÍTICAS DE ANDINOS EN EL SUR DE EUROPA}

\author{
Liliana Suárez Navaz \\ Universidad Autónoma de Madrid
}

\begin{abstract}
This article explores from an ethnographic perspective the political practices of migrants in a transnational public sphere, based in a study case of Andean Ecuadorians in Spain. It emphasizes the connections between the impact of immigrants settling in Madrid and their efforts to maintain a socioeconomic and political presence in their community of origin, looking at the way new practices of transnational citizenship are established in current neoliberal age. It proposes the category of transnational social fields in the bourdieuan sense to scrutinize how territory, identity and residence are redefined to build up a new cartography of inclusion and exclusion from citizenship rights and duties across national frontiers. It offers some empirical findings to illustrate the way new structures of sociocultural stratification are built both in the origin and destiny countries through these new transnational political practices. These insights are contextualized within some key theoretical debates around the new proposals of transnational citizenship.
\end{abstract}

KEY WORDS: International migrations; transnational citizenship; translocal political practices; gobernability; transnationalism.

\section{INTRODUCCIÓN: CIUDADANÍA EN CAMPOS MIGRATORIOS TRANSNACIONALES}

La ciudadanía como modelo político dominante de pertenencia y titularidad de derechos se muestra insuficiente para el gobierno de la movilidad. Las premisas de la ciudadanía están arraigadas en un paradigma territorial y sedentario y una lógica teleológica y estatista de la política y el gobierno. En la era actual el modo de producción capitalista ha profundizado su dimensión internacional hasta límites no previstos por los regímenes de ordenación política y la gestión de las economías nacionales. Si bien es cierto que numerosas transformaciones han venido
ETHNOGRAPHIC THOUGHTS ABOUT TRANSNATIONAL CITIZENSHIP. POLITICAL PRACTICES OF ANDEANS IN SOUTHERN EUROPE

RESUMEN: Este trabajo explora desde una perspectiva etnográfica las prácticas políticas de migrantes en una esfera pública transnacional, en base a un estudio de caso de ecuatorianos andinos en España. Enfatiza las interconexiones que se producen entre el impacto del asentamiento de los inmigrantes en Madrid y sus esfuerzos por mantener una presencia socioeconómica y política activa en su comunidad de origen, analizando el modo en el que las nuevas prácticas de ciudadanía transnacional se configuran en la actual era neoliberal. Se propone la categoria de campo migratorio transnacional en el sentido bourdieuano para profundizar cómo el territorio, la identidad y la residencia se redefinen en una nueva cartografía de inclusión y exclusión de los derechos y deberes de ciudadanía a través de las fronteras. Se ofrecen algunos resultados empíricos que ilustran las nuevas estructuras de estratificación tanto en el pais de origen como en el de destino construidas a través de estas nuevas prácticas políticas transnacionales. Estos hallazgos se vinculan a algunos debates teóricos claves alrededor de las nuevas propuestas de ciudadanía transnacional.

PALABRAS CLAVE: Migraciones internacionales; ciudadanía transnacional; prácticas políticas translocales; gobernabilidad; transnacionalismo.

creando nuevos espacios políticos a nivel internacional y supranacional, la dimensión del gobierno transnacional en los procesos migratorios apenas comienza a explorarse.

En este trabajo realizamos una incursión etnográfica en las prácticas y estrategias que los migrantes ponen en marcha en destino y en origen para, desde el desplazamiento, redefinir su posición en relación a las nociones de pertenencia y titularidad de derechos proyectadas por las sociedades involucradas'. Nos centraremos en el estudio de caso de una comuna de origen quechua situada en los alrededores de Quito, denominada con el seudónimo de Jatum Pamba. La elección de esta comuna responde al 
hecho de su carácter pionero en la migración ecuatoriana en España y en su destacado protagonismo en las prácticas asociativas y políticas en Madrid. Eligiendo una comuna (o comunidad) de origen no pretendo estudiar el modo en que ésta se redefine o se extiende en el contexto transnacional como lo han hecho colegas americanos bajo el concepto de "comunidad transnacional" (Besserer 2000). Como más adelante propongo, es la unidad analítica la categoría de campo migratorio transnacional de la que parto, incluyendo en el análisis de manera sistemática la interrelación de las dinámicas en origen y destino así como la articulación de las estructuras macroeconómicas y políticas con aquéllas que tienen lugar a partir de las redes sociales y comunitarias de los propios migrantes. La elección de una comunidad de origen para el análisis responde más bien al interés de hacer metodológicamente viable el estudio de las múltiples retroalimentaciones entre origen y destino que escapan a una unidad de análisis más amplia. Así pues, cuando estudiemos su asentamiento social en España muchas de sus prácticas serán comunes a otros conciudadanos ecuatorianos y otros migrantes en general. El impacto en origen dependerá en gran medida del contexto local y el tipo de cultura política de partida, y será por tanto una cuestión empírica que debe ser contrastada en cada uno de los casos estudiados.

No obstante, partimos de la premisa teórica de que hay rasgos comunes al tipo de configuración del espacio político transnacional que tienen que ver con profundas transformaciones en la intervención de instituciones políticas y entidades de la sociedad civil en el gobierno de la movilidad. La perspectiva transnacional que propongo (Suárez 2008) estudia las redes migratorias y las estrategias personales y familiares a través de una conceptualización no determinista de las formas de capital que circulan en el campo social transnacional, buscando explicar la articulación y traducción de formas de capital económico, social o simbólico como causa de los múltiples impactos en origen y destino y las dinámicas propias de las redes migratorias. Se explora así la articulación entre niveles micro y macro, entre posiciones en origen y destino, y entre las dimensiones económica, política y simbólica de las prácticas de los migrantes y otros agentes involucrados en las redes.

Este tipo de análisis complejo precisa de una unidad de análisis que reconozca tanto las fuerzas estructurales de tipo macro como las dinámicas instituidas en los agentes sociales, y que no dependa de una visión territorial ni economicista del ejercicio del poder. A mi modo de ver, esta unidad de análisis puede inspirarse en la noción de campo social de Bourdieu: "Los campos se presentan para la aprenhensión sincrónica como espacios estructurados de posiciones (o de puestos) cuyas propiedades dependen de su posición en dichos espacios y pueden analizarse en forma independiente de las características de sus ocupantes (en parte determinados por ellas)". El campo social transnacional (CMT) tiene una dimensión histórica que marca estructuras de poder e imaginarios de largo arraigo social y cultural, como lo es en este caso la relación colonial y neocolonial entre Ecuador y España y su reflejo en el orden económico y político neoliberal. Está condicionado por las normativas nacionales o los acuerdos bi-/inter-nacionales, por los actores económicos, sociales y religiosos involucrados en el gobierno de la movilidad y el diseño de estrategias de "desarrollo" transnacional, pero también por las propias estrategias de los colectivos desplazados frente a las cortapisas al ejercicio de la ciudadanía en el campo transnacional.

Todos los agentes e instituciones involucrados comparten una serie de intereses comunes que les lleva a realizar inversiones estratégicas de capital económico, político y simbólico a través de las diferentes posiciones en este espacio de acción transnacional. Las distintas posiciones de los agentes e instituciones involucradas no remiten exclusivamente a este campo, como es característico en la teorización bourdieuana. Un posición de poder como la de una autoridad política estatal o un empresario nacional se traduce en ventajas y capacidad de influencia en el campo migratorio transnacional. Pero también sucede que un actor con capital social dentro de las redes migratorias transnacionales, un dirigente de la diáspora, por ejemplo, se torna central para la articulación de proyectos de gobernabilidad en los que los anteriormente citados puedan traducir su capital nacional en el campo social transnacional. En otras palabras, la acumulación de poder transnacional no se deduce mecánicamente de la nacional (ni viceversa). El "juego" del campo exige por parte de los actores un tipo de prácticas y de alianzas estratégicas especificas y no deducibles de las dinámicas nacionales y/o territoriales. La autoridad política o el empresario deberán invertir en este campo económica, política y simbólicamente y de hecho así lo están haciendo de manera intensiva, como descri- 
bimos con más amplitud en otros trabajos (Suárez 2009). Los múltiples proyectos de gobernabilidad transnacional de instituciones y agentes de una tradicional raigambre territorial, como la UE, los estados involucrados, o parte de un sector empresarial nacional, buscan nuevos espacios de poder a través de la articulación de sus intervenciones con la gestión de las redes migratorias establecidas en los distintos nodos de asentamiento en el campo migratorio.

Lo característico del campo migratorio transnacional es un proceso complejo de legitimación de la acción de estos diferentes actores a través de las fronteras nacionales. Aunque partimos de la idea de múltiples escalas de la gobernabilidad del campo migratorio transnacional, en este artículo escogemos ilustrar estos procesos complejos a través de la etnografia realizada los últimos años con migrantes ecuatorianos en España y en Ecuador. El estudio de caso nos permite mucho mejor que otras metodologías de corte más cuantitativista explorar en profundidad los procesos sociopolíticos que surgen alrededor del gobierno de la movilidad. Observamos estas estrategias de gobierno en la forma en que se regulan instrumentos que coartan la movilidad tanto como aquéllos que, desde el reconocimiento del potencial de la movilidad transnacional, diseñan programas, directivas y proyectos que involucran la acción sociopolítica de migrantes en origen y destino. Los propios migrantes y sus familias, como protagonistas principales de esta movilidad internacional, se involucran en procesos sociopolíticos de carácter transnacional con el interés de intervenir también en el campo migratorio con su propia idiosincrasia.

\section{Ciudadanía transnacional y gobernabilidad DE LA MOVILIDAD EN LA ERA DE LA GLOBALIZACIÓN}

La ciudadanía ha sido desde la llustración el modelo dominante de gestión política así como de referencia de pertenencia identitaria. La representación parlamentaria de los intereses de un pueblo por parte del estado moderno se legitimó históricamente en base a una común identidad -la nación o etnos- y/o el nacimiento en un territorio bien acotado por sus fronteras. Territorio e identidad cultural definian al pueblo soberano, y aunque estas variables siguen siendo claves en la gestión política, el estado-nación como modelo dominante ha sido transformado sustan- cialmente. La aceptación progresiva del multiculturalismo y de la transferencia de competencias claves de gobierno estatal hacia territorios regionales o supranacionales, asi como el incremento cuantitativo y cualitativo de la movilidad a través de las fronteras sin duda plantea nuevos escenarios para el gobierno de las poblaciones en la era global (Sassen 1998, 2006).

El modelo liberal de ciudadanía descansa además en la idea fundacional de igualdad jurídica entre los ciudadanos, que el Estado garantiza a través de la separación de poderes y la prerrogativa de diseño de políticas públicas orientadas a la redistribución de la riqueza y la cohesión social. Tal como Marshall planteó en su ensayo seminal sobre la ciudadanía, la ciudadanía es el instrumento político idóneo para contrarrestar las desigualdades y falta de cohesión social generadas de manera estructural por el modo de producción capitalista. La dimensión de la ciudadanía social vendría por lo tanto a generar los instrumentos políticos necesarios para contrarrestar el impacto de los aleatorios ciclos económicos y de las dinámicas de explotación generadas por el mercado (1950)².

Hoy en día, la definición de la soberanía y el gobierno se ha complejizado enormemente con la presencia de colectivos de migrantes asentados en las sociedades de destino y con vínculos fuertes y sostenidos de tipo económico, sociocultural y político con su sociedad de origen. La presencia de numerosos colectivos extranjeros de larga residencia sin acceso a todos los derechos de ciudadanía, desde la perspectiva de la sociedad receptora, o bien colectivos de expatriados titulares formales de derechos que difícilmente pueden ejercer desde la distancia, plantean la necesidad de reformular el modelo de ciudadanía nacional. Estos colectivos, que denominaremos migrantes o transmigrantes ${ }^{3}$, se caracterizan por su desplazamiento espacial, social, y político respecto a las autoridades políticas que gobiernan bien el territorio donde viven bien el territorio de donde son originarios. La situación de estos migrantes, con derechos parciales reconocidos en origen y destino exige una perspectiva analítica y un trabajo empírico asociado radicalmente original para poder captar las nuevas modalidades del gobierno de la movilidad transnacional${ }^{4}$.

Fue también Mashall quien dio base científica al argumento de que la ciudadanía, como mecanismo de inclu- 
sión y exclusión, era resultado de un proceso histórico que evolucionaba y se extendía institucionalmente en respuesta de las reivindicaciones que se apropiaban de su motus universalizador. Su análisis se centraba en el modo en que el modelo de ciudadanía en Gran Bretaña había ido expandiendo históricamente el ámbito de los derechos garantizados por el estado (derechos civiles, políticos, socioeconómicos) así como el tipo de sujetos reconocidos como ciudadanos (burguesía con patrimonio, obreros, mujeres, sujetos colonizados). Sus planteamientos fueron posteriormente criticados por unilineales y atrapados en la jaula nacionalista, pero la idea de que la ciudadanía era resultado de un proceso histórico derivado de las reivindicaciones de inclusión por parte de los sujetos excluidos se mantuvo vigente (Somers 1993; Suárez et al. 2007).

Las fuertes transformaciones que de manera evidente está sufriendo el modelo clásico de ciudadanía nacional, vinculada a un territorio y a una nación culturalmente homogénea, han hecho despertar en los debates filosófico-políticos la idea de ciudadanía cosmopolita de Immanuel Kant (Kant 1795; Habermas 1998; Velasco 2007). Este tipo de ciudadanía de alcance universal se vinculaba éticamente con el principio de hospitalidad y es claramente muy relevante en una época que el teórico Castles ha denominado la "era de las migraciones" (Castles y Miller 2004). En su dimensión divulgativa en la esfera política más mediática, el debate sobre el cosmopolitismo se vincula a dos posturas extremas que queremos evitar aquí: bien la que recela de este horizonte cosmopolita como decadencia de Occidente (Huntington 2004; Anderson 1994), bien la que por el contrario lo celebra como una nueva era de mayor y más universal reconocimiento de derechos y libertades (Beck 2005; Appadurai 1996, 2004). Desde una perspectiva más académica, varias críticas al concepto por su sesgo etnocéntrico y por las premisas evolucionistas han mostrado que el cosmopolitismo es, más que un mero horizonte político a "conquistar" o una nueva era en la evolución y expansión de la ciudadanía, un estrato añadido al conjunto de horizontes políticos que se articulan, contradicen y amalgaman en esta era de la globalización (Benhabib 2005; Ong 1999).

La concepción de ciudadanía transnacional debe eludir las premisas epistemológicas de un cosmopolitismo basado en el impulso ilustrado kantiano (Suárez 2006). Definimos el concepto de ciudadanía transnacional como un producto empírico (y por tanto no asumible a priori) del conjunto de prácticas políticas que de manera sostenida se mantienen a través de las fronteras de los estados-nación construyendo nuevos espacios políticos de acción que no eluden los estados (u otros niveles de gobierno territorial) ni sus fronteras, pero que en su sistematicidad los transforman de manera dramática. Mientras que el modelo posnacional o el cosmopolita apuntan a esferas de reconocimiento de derechos mas allá de la ciudadanía nacional, como un escenario normativo abstracto que representa nueva fase de la expansión de la ciudadanía, en este trabajo se defiende una perspectiva teórica y metodológica que se centra en los procesos creados a través de la conexión y desconexión de los espacios públicos generados a partir de las prácticas migratorias ${ }^{5}$.

Nuestro trabajo empírico sobre los movimientos políticos asociados a la movilidad poblacional refuerza la idea de que la posición de los migrantes en la era de la globalidad y de los derechos humanos incorpora tanto como cuestiona premisas básicas del modelo de ciudadanía nacional. Numerosos factores mantienen los ejes nacionales (y/o territoriales o identitarios) de reivindicación de derechos como dominantes entre los modos de incorporación de los inmigrantes, pero existe también evidencia del impacto de normativas de tipo ético como la declaración de los derechos humanos en la concepción de la ciudadanía. Soysal (1994) demostró cómo varios regímenes europeos incluian de hecho (aunque no de derecho) a cientos de miles de extranjeros no ciudadanos como titulares de derechos de ciudadanía tan básicos como los derechos civiles y los derechos sociales. Ella denominó este modelo posnacional y lo consideró como una nueva extensión de la ciudadanía en su camino hacia el desprendimiento de su segunda piel nacional.

Numerosos trabajos de investigación han mostrado cómo los migrantes ponen en marcha estrategias orientadas a crear un espacio político transnacional de prácticas de ciudadanía que involucran a los estados implicados de maneras novedosas: se reclama ciudadanía en base al criterio de la residencia en destino y en base a la pertenencia etnocultural en origen ${ }^{6}$. Este proceso genera un fenómeno de identidades y lealtades múltiples que encuentran difícil acomodo en los marcos normativos nacionales que rigen sus vidas. Por otra parte, el análisis de los nuevos 
espacios políticos asociados a las prácticas de ciudadanía transnacional no deben disociarse de la precaria posición de los nuevos trabajadores migrantes en el mercado laboral internacional. La economía política de la globalización económica y la herencia colonial son base esencial de las nuevas configuraciones que estructuran la desigualdad y la división del trabajo a nivel internacional. Estas esferas de lo público incorporan mecanismos tradicionales y hegemónicos de exclusión e inclusión de gobierno tradicional vinculado a un territorio y una identidad cultural, pero no se agotan en esto. Las actividades de producción e intercambio asociadas a la estructura social en su dimensión transnacional generan relaciones sociales y prácticas que son consecuencia del equilibrio de fuerzas existente entre los distintos grupos e instituciones sociales que forman parte de estos nuevos espacios de participación ciudadana creados a través de los espacios políticos tradicionales acotados territorialmente y definidos culturalmente. Como hemos dicho antes, no nos referimos a un espacio desterritorializado, sino a un espacio transterritorial donde los procesos de gobernabilidad incorporan los vínculos identitarios y territoriales caracteristicos del gobierno estatal tradicional. Las nuevas subjetividades y lógicas de gobernabilidad del espacio transnacional surgirán pues en aquellas prácticas de pertenencia y titularidad de derecho que cruzan fronteras y que se retroalimentan de manera que el ejercicio ciudadano en uno de los polos altere el ejercicio ciudadano en el otro.

A continuación exploramos, a través del estudio de caso de los ecuatorianos de origen indígena en Madrid, el modo en que estas tensiones se expresan en los campos migratorios transnacionales. Mostraremos cómo las transformaciones de la ciudadanía a la luz de los movimientos migratorios en la era de globalización neoliberal abren disyuntivas poco contempladas por modelos como el posnacional o cosmopolita. El escenario no invita a celebrar las transformaciones como una nueva etapa de simple extensión de la ciudadanía, porque muchos son los claroscuros de las nuevas fronteras de exclusión. En la era del mercado global, la porosidad de las fronteras es mayor para los movimientos de las fronteras que para los movimientos de las personas. Nuevas formas de mercantilización global y la reproducción de la etnoestratificación amenazan, entre otros aspectos, ámbitos hasta hoy preservados de la lógica del mercado. La ciudadanía es uno de ellos.

\section{Ecuatorianos serranos en Madrid: la fase DE ASENTAMIENTO Y RECONSTRUCCIÓN DE LA Pachamama en la Meseta castellana}

Los comuneros de Jatum Pamba protagonistas de uno de nuestros estudios de caso y sus paisanos de Quito y sus alrededores son parte de una emigración masiva de ecuatorianos a España que comienza con los albores del presente milenio y que acompaña una de las crisis económicas más graves del país andino. La caída en picado del PIB en 1999, de casi un $30 \%$ en un solo año, según el Banco Central del Ecuador, incrementó los porcentajes de pobreza hasta más del $70 \%$ en el año 2000. Desastres naturales como El Niño, conflictos bélicos como el que se mantuvo con Perú y una profundización de políticas neoliberales se unen a un período convulso a nivel institucional, con derrocamientos de presidentes por mandato popular y reiterados fenómenos de corrupción y deterioro del clima político y socioeconómico en el pais. En 1999 el presidente Mahuad congela todas las cuentas bancarias y se produce una altísima inflación unida a la caída de los precios del petróleo, la suspensión de la deuda externa, y la dolarización del país. La falta total de confianza popular en los políticos mina aún más las esperanzas de recuperación del pais, y la caída en picado de la economía provoca lo que se ha denominado la "estampida" de sus ciudadanos (Ramírez et al. 2003).

La nueva demanda de mano de obra no cualificada en el sector doméstico, la agricultura y el sector servicios en general en el sur de Europa coincide con el cierre de las fronteras norteamericanas, destino tradicional de algunas provincias ecuatorianas como Cuenca. España no exigía visado en aquel entonces ni a los ecuatorianos ni a muchos otros latinoamericanos que se han ido asentando en el país y formando colonias numerosas y arraigadas que han superado con creces la inmigración tradicional de países vecinos como Marruecos. El dato más destacado a nivel cuantitativo es la rapidez y la cantidad de personas que salen del país, contándose hasta 140.000 personas que se establecen en el extranjero anualmente desde 1995 hasta el 2003 (Cartilla para la migración: 2004). 2003 es la fecha en que España impone ya un visado de entrada que ralentiza el flujo: los investigadores que estamos en campo percibimos sin duda una cierta saturación de las redes migratorias y de su capacidad de inserción de familiares, paisanos o compatriotas en un mercado laboral regular, tal y como impone el visado. Pero el flujo no se detiene sino que cambia de signo.

ARBOR CLXXXVI 744 julio-agosto [2010] 639-655 ISSN: 0210-1963 
Así ha sucedido con los migrantes originarios de Jatum Pamba y alrededores. En Madrid los comuneros de Jatum Pamba son pioneros y llegan a partir de mediados de los noventa con cadenas migratorias fuertemente feminizadas, aunque no en exclusiva. Mujeres y hombres de clase media baja, pertenecientes a un proletariado de origen rural golpeado por la crisis ecuatoriana, se endeudan con los chulqueros (prestamistas locales) y se adaptan a las rutas que mejor eluden los controles fronterizos. Tengamos en cuenta que, aunque no se pide visado a los ecuatorianos, la actividad policial en la frontera española detiene aleatoriamente a aquéllos que resultan "sospechosos" en sus intenciones turísticas según criterios que los investigadores no podemos explicar si no es por el efecto de la "política de la no política" (Calavita 2005). Inicialmente muchos entraron por Holanda como país de tránsito para ser bienvenidos en España con un visado de turista que les colocaba apenas en tres meses en una situación irregular. Todos los migrantes que he conocido llegaron con algún contacto que les facilita la primera búsqueda de vivienda y trabajo, y pronto se insertan en las cadenas laborales de servicio doméstico o construcción, obviamente de manera irregular. Las deudas iniciales proliferan, tanto la que adquirieron en Ecuador como la que, a menudo, contraen con miembros de las redes migratorias, amigos y/o familiares que capitalizan el asentamiento inicial.

A pesar del visado y de las dificultades impuestas por la irregularidad de su situación en destino, los comuneros continúan el éxodo. Trabajo duro, separación familiar y endeudamiento masivo son tres de las caracteristicas de esta etapa inicial. Se produce pronto un choque entre el gobierno de una migración pretendidamente laboral, con fuertes limitaciones para la reagrupación familiar, y los deseos de los migrantes en convertir ese proceso migratorio en algo más integral que la mera búsqueda de un trabajo. En muy pocos años, y a través de un durísimo esfuerzo colectivo e individual, se transforma desde abajo el carácter de una migración tolerada por sus beneficios en el mercado laboral. Como regla general tardan un par de años en activar sus redes para conseguir realizar una reagrupación familiar a través de canales informales. Para iniciar este proceso es suficiente con contar con un pequeño espacio propio, a menudo una habitación que alquilan a paisanos o compatriotas, para volver a endeudarse y traer al cónyuge o a los hijos. Las Leyes de Extranjería no reconocen este proceso de reagrupación informal, con lo que gran parte de la comunidad se asienta en condiciones de irregularidad. Pero de hecho, aunque no de derecho, alteran sustancialmente el tipo de asentamiento temporal e irregular que les estaba reservado.

El trabajo irregular es ampliamente tolerado en un país como España, con altísimas tasas de economía informal que comparten con los trabajadores autóctonos, aunque progresivamente se viene imponiendo un imaginario que construye la irregularidad de la mayor parte de los inmigrantes en España como un "problema" que el Estado oferta solucionar con sus programas extraordinarios de "regularización" o "normalización" (Suárez y Arango 2001, Suárez 1998). No obstante, los "sin papeles" en España pueden empadronarse $y$, de hecho, lo hacen como requisito para acceder a la salud o a la educación de sus hijos. En los hospitales, las jóvenes comuneras y ecuatorianas en general se dejan notar por su impacto positivo en el saldo demográfico. En las escuelas los niños se integran con más o menos desajustes al sistema educativo español. Con el agravante de mantener intermitentemente los permisos de trabajo o bien el pago como autónomos a la seguridad social (caso de muchas empleadas en el desrregularizado sector doméstico), los comuneros acceden a una ciudadanía precaria pero que al menos cubre las necesidades básicas de salud y educación. Este acceso a la ciudadanía social es altamente valorado por los inmigrantes, especialmente por las mujeres que siguen haciéndose cargo de la reproducción doméstica, y será un aliciente para invertir dinero, trabajo y esfuerzo en el polo español del campo migratorio transnacional.

Por ello de manera informal continúan los flujos, de manera que podemos conceptualizar esta movilidad a través de las fronteras (y en contra, de hecho, de las normativas que las regulan) como estrategias colectivas de acceso a ciertos espacios transnacionales de acceso a una ciudadanía social sustantiva, aunque precaria.

Veamos este proceso ahora desde una perspectiva transnacional. Las familias asentadas en regiones tan remotas como Pichincha o Madrid son, a pesar de su dispersión residencial, unidades sociológicas de análisis en tanto que mantienen intereses socioeconómicos y afectivos comunes y elaboran estrategias de sobrevivencia transnacionales. El acceso en España a esta precaria pero sustantiva ciudadanía social es valorada como una posición estratégica 
en relación a los miembros que quedaron en origen. Es interesante subrayar el hecho de que este acceso parcial y precario a la ciudadanía social en España se yuxtapone a una redefinición de la relación de los emigrantes con el sistema político ecuatoriano. Su vínculo está marcado fundamentalmente por su capacidad financiera. Éste es uno de los "costos ocultos" de los procesos migratorios: la reducción de la ciudadanía de origen a una relación que se mide en cantidad de remesas enviadas ${ }^{7}$. Las familias dependen de estas remesas y el propio Estado ecuatoriano comienza a valorizarlas en su presupuesto dado que alcanza ya en 2006 los 2.900 millones de dólares según el Banco Central del Ecuador, muy cerca del petróleo como primera fuente de ingresos del país. Pero la orientación transnacional de los Jatum Pambeses no es reducible al aspecto financiero, por supuesto. El vínculo transnacional responde en esta primera etapa de asentamiento a la importancia estratégica de las remesas para la reproducción social y el cuidado de los más jóvenes y los mayores, y el enorme peso de la nostalgia del terruño y de las costumbres de la comuna. No obstante, el tipo de prácticas de ciudadanía de emigrantes cuyo vínculo privilegiado se "mide" a través de sus contribuciones económicas va a alterar su posición en el campo migratorio transnacional, provocando a su vez multitud de transformaciones en patrones microsociológicos de distribución del poder a través de los ejes de género y generación (Herrera et al. 2005, Parreñas 2005, Pedone 2005, Suárez et al. 2006, 2007), y también en lo que afecta en las prácticas de ciudadanía local, como veremos más adelante.

En España poco a poco los comuneros se van asentando en Madrid y sus alrededores y gradualmente algún otro miembro de la familia va logrando los deseados "papeles", aunque las condiciones laborales no mejoran sustancialmente para la gran mayoría de los comuneros y ecuatorianos. El asentamiento en España y su acceso a la ciudadanía social permite crear nuevas estrategias colectivas para la reivindicación de espacios públicos, lo que denominaremos arraigo territorial de la ciudadanía transnacional. En Madrid, por ejemplo, los Jatum Pambeses se reúnen en el Parque del Oeste inicialmente, y desde allí organizan informalmente la venta de comida, la ocupación de las pistas deportivas y la limpieza del parque por comandos seleccionados entre los propios asistentes. A partir del 2001 comienzan además a ser visibles algunas asociaciones socioculturales y políticas como Apem (Asociación Pueblos del Ecuador en Madrid), o la Conadee
(Coordinadora Nacional de Ecuatorianos en España), todas ellas fundadas con dirigentes que provienen de Jatum Pamba. Los objetivos de estos grupos pasan por la conquista de espacios públicos, inicialmente en su dimensión más estrictamente socioespacial: parques, plazas, campos deportivos y locales para la celebración de fiestas y eventos colectivos. Los primeros objetivos se centran en crear espacios de socialización que no sean penalizados por la policía, organizando la comida y bebida que se oferta, el deporte, e incluso las fiestas y bailes comunitarios. Ya en esta fase se van distinguiendo subgrupos por adscripción nacional, étnica o de paisanaje, como es el caso de los comuneros de Jatum Pamba:

"ellos son los iniciadores de las reuniones en el parque del Retiro [a primeros de los noventa]... más que nada porque ninguno de ellos tiene vivienda más que la de sus patrones porque ellos son internos, ninguno trabaja en otra cosa. Entonces los domingos, el día libre, lo único que pueden es encontrarse en común primero el punto de reunión de los de la comuna [de Jatum Pamba]... por ahi empiezan a hacer un poquito de actividad deportiva, y tampoco vendían nada sino que solamente era para brindar ellos no más. Pero la gente sigue y sigue viniendo... y ya no sólo llevaban para brindar, sino para vender, un tipo de comercio emergido de comida y bebida. La policia es drástica, muy drástica y... como son gente fácilmente identificable porque llevan mochilas, llevan la cerveza y cosas, les quitaban todo y ya ahi unos 4 deciden buscar otro sitio en donde nuevamente reunirse y por más de todo poder jugar el ecobol, ... buscando un sitio pero que no ande muy lejos del metro ¿no?... el Parque del Oeste. Entonces la gente pregunta, por que eso es lo que hace cualquier inmigrante cuando llega a un país, pregunta donde están los ecuatorianos, y les dicen pues en el Retiro y en el Parque del Oeste pero... la diferencia es que en el Parque del Oeste hay sólo ecuatorianos y más de la zona andina de Calderón y de Quito y sus alrededores... en el Retiro también hay gente vendiendo pero es una mezcla de peruanos, colombianos y ecuatorianos... en el Parque del Oeste sólo ecuatorianos. La esencia es el querer compartir... Españoles van pocos, es que nos tienen miedo. Claro un poco creo que la situación es natural... Cuando empezaron a bajar los mestizos que son ecuatorianos mismos nos empezamos a sentir molestos. Era como que estaban invadiendo nuestra Pachamama. No nos estaban invadiendo ni nada pero como está tan inculcado eso de la propiedad colectiva pues eso se ve" (Lider comunitario, 2002).

ARBOR CLXXXVI 744 julio-agosto [2010] 639-655 ISSN: 0210-1963 
Según se van asentando y consolidando su proceso de colonización familiar, se crean grupos de baile, se realizan las fiestas propias del ciclo vital y cultural, con rituales y peregrinajes que recrean las celebraciones patrias e indígenas en la diáspora (Suárez 2007). El deporte es uno de los motores de la organización colectiva, con asociaciones como Apem dirigida por jatumpambeses que tienen los más altos índices de convocatoria de la comunidad ecuatoriana en Madrid. Los partidos suelen ser semanales, organizándose en campeonatos deportivos de todos los niveles de edad y con múltiples escalas de competición (por nacionalidades, "nativos" contra "inmigrantes", a nivel de barrio, municipal, autonómico, nacional o transnacional, como el que organizan los Otavalos cada año durante el Pawcar Raymi del solsticio de invierno, etc.).

Éste ha sido un proceso vertiginoso que asombra al investigador conocedor de otros colectivos de inmigrantes. Pronto los Medios de Comunicación de la Diáspora, creados a partir de estructuras financieras precarias dependientes de la publicidad dirigida hacia los colectivos de inmigrantes, se convierten en voceros de estas actividades, a través de un sistema artesanal de distribución en los nodos de la comunicación intracomunitaria transnacional, como son los locutorios $^{8}$. Como es lógico, el tejido social que se trenza alrededor de estos nuevos espacios públicos conquistados es cada vez más complejo, incluyendo también organismos públicos que intervienen con programas de "ordenación y control del territorio", o "mediación comunitaria", así como numerosos agentes empresariales que buscan esta nueva clientela particular a través de comerciales, dirigentes comunales y asociativos, financiación de eventos, publicidad en los medios, o propaganda con un caracteristico marketing de sabor "étnico". Veamos ahora el proceso asociativo más estrictamente político, sin olvidar, como lo hacen muchos trabajos, que sin esta capacidad de arraigo colectivo de tipo territorial el movimiento asociativo sería como un gigante con pies de barro.

\section{Construcción de UNA CIUDADANÍA DIFERENCIADA EN EsPaña Y dE UN NUEVO ESPACIO SOCIOPOLÍTICO TRANSNACIONAL}

Es de hecho alrededor de estas primeras estrategias colectivas de arraigo socioespacial en territorio español que cuajan las primeras asociaciones de inmigrantes de corte más explícitamente político. Para desarrollar estas actividades se genera un estrato dirigente entre los migrantes que se encarga de realizar los contactos pertinentes con las administraciones públicas. La conquista del uso de muchos parques públicos (el parque del Oeste, el Retiro y otros en Madrid como hemos visto antes), y de instalaciones deportivas es un bien común sobre cuyo control se ejercen procesos de lucha y de negociación muy relevantes para un análisis de las políticas de asentamiento. El movimiento asociativo va creciendo y se añaden asociaciones de corte más claramente político, como Rumiñahui, y nuevos espacios políticos a través de la cooperación de numerosas asociaciones en los planes de integración locales o regionales, como la Fenadee, o Federación Nacional de Asociaciones de Ecuatorianos en España. A través del complejo panorama del movimiento asociativo de los comuneros y los ecuatorianos en general observamos claramente el vínculo empírico existente entre el acceso a la dimensión socioespacial de la ciudadanía en España y el intento de construcción de una ciudadanía diferenciada en el espacio político español, que se construye en articulación con la creación de espacios públicos transnacionales.

La ciudadanía diferenciada ha sido desarrollada por teóricos como Iris M. Young (2000), en su crítica frontal a la idea de ciudadanía como proceso individual de reconocimiento y titularidad de derechos. Los individuos que forman estos nuevos colectivos de inmigrantes han accedido parcial y precariamente a la ciudadanía social, pero es sólo a través de los procesos colectivos de visibilización de su participación en los espacios públicos que comienzan a hacerse un lugar en la negociación pública por la representatividad de intereses diferenciados de la ciudadanía española. La sociedad española, con su modelo mixto aunque titubeante de incorporación de inmigrantes, predica la inclusión de los migrantes en igualdad con el resto de los ciudadanos (al servicio de salud, de educación, de derechos de asociacionismo y sindicación, de retribuciones al desempleo), pero a la vez dibuja un escenario político donde la diferencia cultural es una de las bases de reivindicación de derechos. El estado español, con sus comunidades autónomas y su transferencia de competencias al ámbito autonómico, ha legitimado durante el proceso de transición la articulación de un sistema de gobierno cuasifederal basado en las diferencias culturales y territoriales. Si bien es cierto 
que las españolas son diferencias basadas en argumentos históricos, las nuevas diferencias tienen hueco en este sistema, que Kymklica denominaria de diferencia profunda, al combinar diferencias culturales "autóctonas" con otras diferencias de minorías culturales no territoriales, como los gitanos y las minorías generadas por los recientes procesos migratorios (1996). Eso sí, y aunque sea brevemente es preciso comentarlo, el tipo de ciudadanía diferenciada producido no responde al más complejo modelo de Young, en donde las cuestiones relativas a la etnoestratificación y sexismo son fundamentales, sino a un modelo multiculturalista de tipo liberal.

Así pues, los ecuatorianos inician como muchos otros colectivos de inmigrantes un proceso de negociación que, basándose en su arraigo territorial, reivindica su acceso a espacios sociopolíticos en todos los niveles de gobierno -municipal, autonómico, nacional-. Aunque no puedo extenderme en los claroscuros de esta incorporación a la estructura política en España, lo cierto es que las autoridades en todos los niveles de gobierno crean puentes con los representantes de los colectivos de inmigrantes. Estos puentes no son fruto exclusivo de procesos políticos de inclusión democrática desde arriba, como resultado de un modelo posnacional de reconocimiento de los derechos de los trabajadores migrantes, à la Kant o à la Soysal. Por el contrario responden a dos tendencias paralelas: por una parte, el debate sobre la transformación del derecho al voto en el contexto de la Unión Europea y, por otra, el cambio en el modo de gobierno, hacia una gobernabilidad que incorpora en tareas de gobierno al denominado "tercer sector" (cf. Suárez 2009).

A efectos analíticos, este proceso de acceso de los espacios públicos se ha caracterizado por tres importantes características. En primer lugar, se produce una enorme proliferación de asociaciones de ecuatorianos, de índole territorial, sociocultural y/o deportiva, o más explícitamente políticas, y surge una fuerte competitividad entre distintos dirigentes y proyectos sociopolíticos, tanto en relación a sus bases como a instancias financiadoras. En más de una ocasión he escuchado decir que el régimen de subvenciones que caracteriza la sociedad civil española, e incluye tanto ONGs como instituciones públicas municipales, regionales y nacionales, habían hecho mucho daño al movimiento de los inmigrantes porque "la gente se arrima por la plata y no por el interés de los migrantes".
El mantra más repetido en las convenciones de las federaciones y de encuentros de inmigrantes es la necesidad de unión entre los múltiples esfuerzos organizativos. Como muestra una anécdota etnográfica de la última reunión convocada por la SENAMI [Secretaria Nacional (ecuatoriana) de la Migración] en la que se pretendía que participasen todas las asociaciones de ecuatorianos presentes en España. Se realizó una dinámica en la que se invitaba a los asistentes a romper un palito, dos palitos, y hasta un grupo de palitos, reiterando una y otra vez cómo es imposible romper incluso un frágil palito si está unido con otros (abril 2008, Madrid).

En segundo lugar, se produce también una diversificación del espectro político con el que se relacionan los dirigentes inmigrantes. A partir de las iniciativas de base surgidas en los procesos organizativos antes mencionados, surgen dirigentes que van acercándose a las autoridades españolas en el municipio de Madrid, la Comunidad de Madrid, o la Secretaría del Gobierno central, bien directamente 0 a través de algunos de sus mediadores en la sociedad civil, las ONGs. Se inicia y fortalece un proceso de cooptación de una sección del liderazgo inmigrante por parte de las autoridades y sociedad civil españolas que en no pocas ocasiones debilita el movimiento asociativo. Algunos intentan mantener conexión con las bases (potenciando intereses populares como son el apoyo a la venta de mercancías, al deporte, 0 a actividades religiosas), en otros casos se produce una separación más clara entre los nuevos liderazgos y sus bases, que se manifiesta en la energía dedicada a actividades más institucionalizadas y cercanas al panorama asociativo español. Algunos trabajos de investigación sobre las asociaciones participantes en el foro de los inmigrantes sugieren que los propios dirigentes resienten estos procesos, generando una "integración en profundidad", esto es, la que existe entre los dirigentes y sus bases, debilitada (Toral, 2009).

En tercer lugar, muchas de estas asociaciones se construyen y fortalecen en un espacio público transnacional que incorpora interlocutores tanto nacionales como transnacionales: los estados de origen y destino, la sociedad civil transnacional y nacional a la que se adscriben mediante complejas alianzas, y, por supuesto, las redes personales, familiares y comunitarias a las que se vinculan sus líderes tanto en origen como en destino. La transnacionalidad de este espacio público no siempre es favorecedora del movi- 
miento asociativo. Es difícil trabajar las múltiples lealtades y necesidades de los migrantes transnacionales, porque en los espacios públicos apoyados por las autoridades nacionales o regionales prevalece un enfoque de la política muy territorial y nacionalista. No obstante, hay un esfuerzo sostenido por mantener una red de contactos transnacional, de forma que todo tipo de interlocuciones políticas (con el gobierno español o madrileña, con la embajada ecuatoriana o la Secretaría Nacional del Migrante, de reciente creación, la SENAMI, con otros dirigentes migrantes ecuatorianos, latinoamericanos y otros colectivos -en este orden-) son valoradas como capital social de la persona y/o de la asociación que representa.

La proliferación y competencia entre asociaciones, la ampliación del espectro político y de las relaciones de las mismas con distintos sectores de la sociedad española, y la transnacionalización de sus prácticas son, pues, tres rasgos claves en el movimiento asociativo ecuatoriano. En cuanto a los contenidos simbólicos de referencia identitaria producidos en los elementos discursivos y las prácticas desarrolladas por los comuneros y sus asociaciones en este espacio público transnacional destacamos tres: a) la absoluta preponderancia de la construcción identitaria basada en la nación/comunidad de origen (el ser ecuatoriano/indígena), tanto frente a las instituciones (de origen y destino) como frente a otros sectores de la sociedad civil y entre ellos mismos; b) sin bien la cuestión identitaria es prevalente a nivel discursivo y a menudo organizativo, ésta se construye como parte de la condición inmigrante, fuertemente configurada por su posicionamiento de clase y étnico que les sitúa en el sector más bajo y altamente segmentado de la sociedad española, y, finalmente, c) la noción de derechos como ciudadanos transnacionales se genera más bien a partir de la conjunción de las anteriores que de una serie de reivindicaciones más cercanas al discurso universalista de los derechos humanos. En cierta medida, podemos describir el espacio público transnacional como un conjunto estructurado de posiciones en donde prevalecen las prácticas de ciudadanía con arraigo territorial y dominio de las interlocuciones nacionales. A la vez, es destacable el hecho de que más que estructurarse a partir de estrategias de asimilación este espacio público transnacional se construye en base a una idea de ciudadanía diferenciada apuntalada principalmente a través de la capacidad de gestionar redes políticas complejas de tipo transnacional.

\section{LA PERSPECTIVA DE ORIGEN: PRÁCTICAS TRANSLOCALES DE CIUDADANÍA EN EL ESPACIO PÚBLICO TRANSNACIONAL}

Además de las prácticas de asentamiento familiar y colectivo en España y en la esfera pública transnacional, es preciso analizar el impacto de la emigración en la comuna y los procesos de lucha y negociación sobre las normas locales de pertenencia y titularidad de derechos. En Jatum Pamba éstas remiten a una comunidad indígena originaria y a una fuerte identidad como serranos de Ecuador (frente a, por ejemplo, las regiones de la costa). Los miembros de Jatum Pamba lo son por el derecho de sangre, y las familias indígenas que pueblan la comuna, hablen o no Quichua, migrantes o residentes en la comuna, lo son por descender de los miembros de la comuna.

La comuna está situada al noroeste de Quito, a unos 2.600 metros de altitud. Pertenece a la parroquia de Calderón y su máxima autoridad es el Cabildo, institución heredera del pasado colonial y los regímenes de gobierno autónomo, que agrupa 17 barrios distintos y más de 15.000 personas, según el censo de 2001. Desde hace décadas los Jatum Pambeses se integraron en una posición subalterna en el sistema mundial, primero a través del régimen colonial de las haciendas, luego a través de la labor proselitista de unos evangélicos norteamericanos que instauraron una escuela de oficios en la comuna, inculcaron discursos sobre la "necesaria modernización de los indios" y dividieron religiosamente la comunidad (aunque esto último no parece ser muy relevante en las luchas políticas hoy en día). Pronto se incorporan como mano de obra en la metrópoli de Quito como asalariados, especialmente los varones. El imaginario comunitario se vincula con procesos de lucha por la autonomía de la comuna en relación a los poderes de Quito, así como por la reivindicación de derechos que consideran les son negados por su condición de periféricos de una megalópolis como Quito. El impacto de los procesos de modernización a los que nos referimos debilitó en extremo las raíces indígenas de la comuna, aunque mantienen el cabildo y la forma de organización comunal con mingas para las obras públicas que suponen un alto nivel organizativo.

Desde Jatum Pamba la primera emigración de los comuneros está todavía muy presente. Fue el inicio de cientos de vecinos o familias que abandonan la comuna para 
iniciar un proyecto migratorio en España. Los primeros años fueron duros. Atrás dejaron sus hijos al cuidado de los familiares, y les llevó tiempo asentarse para poder traérselos o mejorar la cantidad y ritmo de las remesas. En Jatum Pamba la crisis ecuatoriana del 2000 pegó muy duro y muchas familias apoyaron a algún miembro para que iniciara un proyecto migratorio, dado que los primeros emigrantes consiguieron pronto trabajo y se veía cómo progresivamente iban mandando dinero para la familia o iniciaban procesos de reagrupación familiar. Pronto la nueva "riqueza" de los emigrantes se dejó notar en la comuna. Muchos construyeron nuevas e imponentes residencias en su pueblo de origen. $Y$ lo que es muy importante en nuestra atención a las dinámicas de la ciudadanía: una nueva mano de obra llegó a ocupar puestos de trabajo creados por los emigrantes afroecuatorianos pobres de la costa, denominados "monos" por parte de los ecuatorianos andinos.

Jatum Pamba muestra una mirada ambivalente sobre la migración. Aunque se reconoce como una estrategia de supervivencia exitosa, se apuntan a los costes locales de la emigración: niños dejados atrás en manos de ancianos o familia extensa, nueva estratificación producida por el insumo de capital -enriquecimiento de los emigrantes y llegada de los nuevos inmigrantes de la costa como mano de obra barata-, la inversión en bienes de consumo inmobiliarios que poco favorecen al bienestar colectivo de la comuna, y progresiva mercantilización de las instituciones políticas locales, como pueda ser la minga -trabajo colectivo basado en la reciprocidad-, o las celebraciones comunitarias.

Los migrantes residentes en España se sienten muy vinculados a su comuna de origen. A menudo vuelven para celebrar bodas, comuniones, o bautizos. Invitan a toda la comuna (excepción hecha de los nuevos inmigrantes costeños, por supuesto), y organizan grandes fiestas que los lugareños disfrutan. Estas prácticas han sido descritas exhaustivamente en la literatura a partir de conceptos heuristicamente muy potentes como el de remesas sociales o la idea de la traducción de capitales en el campo migratorio transnacional al que nos hemos referido arriba. Es claro que los procesos migratorios construyen estos campos sociales donde la ausencia se trata de contrarrestar a través de la inversión de remesas económicas o sociales en la comunidad que crean nuevas formas de movilidad social en la estratificación local desde afuera del territorio (Levitt et al. 2004, Guarnizo et al. 2003, Goldrin 2002, Suárez 1996, 2007).

Este proceso es claro en el caso de Jatum Pamba, pero aquí quisiera ir más allá y mostrar cómo el hecho mismo de la ausencia en el territorio impacta en el tipo de normas étnico-políticas de pertenencia y redistribución a nivel local. Un dirigente Jatumpambés no emigrante me hizo un análisis muy sugerente sobre el impacto que estas prácticas socioculturales tienen en las normas profundas de gestión de la convivencia a nivel local:

"JP: Verá, un sólo ejemplo puede servir para perfilar lo que está sucediendo con los migrantes aquí... últimamente han acostumbrado los migrantes a llegar acá a Jatum Pamba y hacer grandes fiestas. No se casan allá, vienen a casarse acá. Aquí se acostumbra por cada individuo acercarse con java [paquete de cervezas] que cuesta tanto, una botella que cuesta tanto, el regalo que cuesta tanto y los sucres o los dólares que cuestan tanto. Estará yendo por 200, 120 dólares, 100 dólares, 60 lo menos o 30 dólares cada uno, e invitan a 500 personas, y como llegaron de España y tienen plata para hacer la mejor orquesta y la mejor presentación... disco móvil u orquesta, o ambas cosas... ¿entonces que es lo que sucede?, yo veo esta figura y no es mía, sino que la observación es de un señor de acá de (...) los migrantes: 'oye compañero vienen, hacen sus fiestotas, comen bien, pasan bien, la gran fama, recogen todos los regalos, empaquetan, se van y nunca vuelven para regalar a los demás, nada'

$P$ : o sea, la reciprocidad...

JP: el 'randi randi' está destruido y por otro lado, todo lo que gastamos en ostentosidades, en el alquiler de los cinco toldos gigantes para reunir 500 personas, en la gran orquesta que pagamos, se fue la plata en el gran show, de los mariachis o de cualquier otra cosa y del disco móvil, y del buffet de la comida, en realidad la comida costó un dólar cincuenta por persona o dos dólares cincuenta por persona, eso es lo que comió en individuo de reciprocidad, y nunca más vuelve. Es una costumbre que nos está haciendo pedazos a nosotros, están llevando nuestros regalos, nuestras platas y no hay quién lo devuelva cuando nosotros hacemos lo nuestro" (Vecino, Jatum Pamba, julio 2005).

Igualmente sucede en relación a las normas locales en relación al trabajo mancomunado: la minga exige la presencia activa y la participación con el trabajo como uno

ARBOR CLXXXVI 744 julio-agosto [2010] 639-655 ISSN: 0210-1963 
más. Pero, ¿qué sucede en estos casos con los emigrantes? Si tienen familiares, se harán cargo de la participación obligada trabajando por ellos. Pero la sangría de jóvenes y adultos en edad activa ha sido enorme, con lo que muchas veces quedan sólo los padres mayores y sus nietos: "el problema es que somos puros viejos, los hijos se fueron, no podemos cocinar ni trabajar en las mingas, asi que mi hijo nos dice, paga y que vengan a hacerte el trabajo" (Vecina de Jatum Pamba, madre de emigrante, verano 2005). Los emigrantes sólo pueden mantener su pertenencia a la comunidad y acceder a los servicios que se están proveyendo colectivamente mediante su participación en la mingas. Si no tienen familiares tienen que alquilar la mano de obra que les sustituye. Los jornaleros contratados a tal efecto, sin embargo, no son considerados miembros de la comuna a pesar de que residen allí: "R-Esos no son de aquí, sólo vienen a trabajar, no son de la comunidad, vienen, se les paga y se van" (ibidem).

Dos cuestiones a señalar en esta última cita. Por una parte, la ausencia de los transmigrantes unido a su capital económico ha producido una fuerte mercantilización de la minga, un proceso que impacta directamente en los principios sociales que rigen la minga. Por otra parte, subrayo la forma en que se sitúa a los nuevos inmigrantes en la comuna, los afroecuatorianos que han llegado a trabajar. La minga funciona como una forma de gestión de la ciudadanía local, con una cara inclusiva y otra exclusiva, la que niega participación en la gestión de lo público a través de la inclusión en los turnos de trabajo mancomunado para poner la alcantarilla o el pavimento (Suárez 2007).

A pesar del severo impacto de la mercantilización, la minga sale reforzada en este proceso porque se reconoce la importancia de su convocatoria y refrendo a los miembros de la comunidad. Los emigrantes redefinen su participación como ciudadanos en la minga a través de su capacidad económica, adquiriendo capital simbólico y social a cambio de su inversión económica. Pero, al tiempo, el reforzamiento de la validez de la minga como expresión de la comunidad étnica sirve para reforzar la exclusión de los derechos como ciudadanos de otros trabajadores ecuatorianos, en este caso, los que no tienen redes con los emigrantes y los que acuden a la demanda generada por su inversión económica, los nuevos inmigrantes de origen afroecuatoriano.
Veamos, sin embargo, cómo no siempre la inclusión de la comuna en un campo social transnacional genera efectos que reproducen estructuras de exclusión y fuerzas de etnoestratificación en origen. En concreto, el modo en que el capital político adquirido en destino juega un efecto contraproducente respecto a la reproducción de las normas de pertenencia y titularidad de derechos tradicional de la comuna que acabamos de describir. La nueva identidad de clase y étnica del migrante en España, y su lucha por el reconocimiento y la titularidad de derechos en los últimos años, afecta de manera rotunda al modelo de gestión de la pertenencia y la titularidad de derechos en la comuna de Jatum Pamba y en Ecuador en general. Las cadenas de migraciones producen contradicciones manifiestas, dado que simultáneamente existen la reivindicación de la pertenencia y titularidad de derechos en España por trabajar y residir alli, y la exclusión de facto de estas nuevas poblaciones en base a su no pertenencia a la comunidad histórica de Jatum Pamba. Esta contradicción se presenta muy claramente en el siguiente extracto de un grupo de discusión con una familia transnacional que tiene a los dos papás mayores y alguno de los hijos en Jatum Pamba y muchos otros en España:

Mujer joven emigrante en Madrid (familia política): creo que hasta... no sé si me gusta... que haya gente desconocida aquí, porque nos hemos ido muchísimos, de mi familia, mismo estamos todos, padre, madre, mis hermanos están allá, mis sobrinos están allá... aquí queda la familia de mi padre, o de mi madre...

Antropóloga: y ¿cuándo ustedes vuelven a Jatum Pamba qué creen, qué ven que necesitaría Llano Grande, qué ven que se podría... hacer, mejorar, o a lo mejor no les falta nada... o qué cosas piensan ustedes desde alli?

Abuela y madre de siete emigrantes que reside en J.P. :...ya no hay quien vaya (...), un moreno, colombiano, peruano... en algún momento ya... me asusta a mí...

Antropóloga: le da miedo... [se crea un silencio incómodo, la abuela sigue opinando]

Abuela: usted no puede andar de día sola, porque yo antes subía, yo antes tranquila bajaba, tranquila subía... ahora me da miedo estar, porque ¿y si encuentro gente desconocida? Hay más gente de afuera...

Antropóloga: claro, es el desconocimiento

Hermana mayor emigrante en Madrid: yo lo que creo es que es inevitable, no? Todos los (...), toda la gente se va, a otros paises o a otros... 
Hermana mediana emigrante en Madrid: es lo mismo que... allá dicen de nosotros, los españoles igual están diciendo: "no queremos que venga más gente" porque antes no se oía mucho de ecuatorianos, pero ahora hay bandas juveniles de ecuatorianos, que... y ahora en la televisión salen... o sea, que tantos ecuatorianos... o un ecuatoriano ha violado a una chica, ha matado... entonces igual está España y los diferentes países, diciendo: "no queremos que nadie venga más porque nos da miedo"

Antropóloga: ya...

Hermana mediana emigrante en Madrid: porque dicen que es cuestión de... igual nos dicen a todos los ecuatorianos, o los inmigrantes... habrá entre ellos, habremos, gente mala, gente... claro, como en todos sitios, igual aquí [en Jatum Pamba], digo... hay gente desconocida, pero no toda la gente será mala, no toda la gente viene a robar, sino que es un fenómeno nuevo que ha pasado, y que la gente tiene que... acostumbrarse, tiene que asimilar, yo creo que a la gente mayor le cuesta más, pero a la otra gente... yo creo que el tiempo les va ayudar a conocer a esa persona nueva que está viniendo a integrarse...

Este debate es un claro ejemplo del modo en que se produce un aprendizaje de los derechos de ciudadanía desde la posición excluida del inmigrante reciente sin papeles, con trabajos precarios, mirada con recelo por la población dominante. Esa vivencia de la exclusión, y del racismo común que la suele legitimar, hace que estas transmigrantes objeten a su madre una norma consuetudinaria de forma que antes del proceso migratorio nunca hubieran siquiera imaginado. Este aprendizaje puede o no traducirse en reivindicaciones de inclusión de los nuevos inmigrantes en Jatum Pamba, pero al menos existe la extensa creencia de que un inmigrante merece reconocimiento, como producto de su experiencia en España.

\section{6. ¿Ciudadanía transnacional? Redefinición DE La CIUDAdanía a PaRTIR DE La CONSTRUCCIÓN DE ESPACIOS POLITICOS TRANSNACIONALES}

El proceso que hemos descrito desde el trabajo de campo multilocal desvela la complejidad y las múltiples contradicciones que genera la lucha por el reconocimiento de derechos en el campo migratorio transnacional. La incorporación activa tanto de las poblaciones expatriadas en los países de origen (aceptación de doble nacionalidad, activación del voto en el exterior, valoración económica del peso de los emigrantes en el desarrollo nacional y local) marca un punto de inflexión en el gobierno de las diásporas. Este proceso, denominado ciudadanía externa 0 ciudadanía extraterritorial ha sido confirmado contundentemente por múltiples estudios con perspectivas empíricas multidisciplinares (Fitzgerald 2000, Moctezuma 2005, Guarnizo 1998, 2006). Al mismo tiempo, en las sociedades de origen se produce una inclusión en la ciudadanía social que, si bien está caracterizada por su parcialidad y falta de estabilidad, genera procesos de arraigo territorial e incorporación "diferenciada" de las diásporas de colectivos de origen (Ostergaard 2003). Este proceso, que Soysal (1994) denominó ciudadanía posnacional, se ve reforzado por otras tendencias descritas en la literatura, como la tendencia hacia la aceptación de ciudadanías múltiples, como la doble ciudadanía, que la UE, por ejemplo, ha adoptado como norma en la Convención Europea sobre la Nacionalidad de 1997. El propio proceso de construcción del espacio político europeo y el horizonte de una ciudadanía supranacional europea que, aunque debilitada por los referéndums en países como Francia o Irlanda y una creciente apatía del electorado europeo patente en los altos niveles de abstención, genera también un nuevo espacio político desde donde se cuestiona la univocidad primordial que estaba en la base del modelo de ciudadanía nacional, hoy por hoy, aún dominante.

La categoría de ciudadanía transnacional a menudo se ha interpretado como un horizonte de reconocimiento de derechos a nivel global, inspirándose en la idea de ciudadanía cosmopolita kantiana. La creciente importancia de los derechos humanos desde la Segunda Guerra Mundial apunta a un espacio de titularidad de derechos independiente de su base territorial e identitaria. Sin embargo, en éste y otros trabajos hemos sugerido que esta acepción de ciudadanía transnacional es a la vez limitada y equivoca, pues elude al menos dos aspectos claves en la configuración del espacio político global. Por una parte, elude incorporar en el análisis la desigualdad heredada y reproducida a través de distintos instrumentos de extracción de la riqueza, posición que hunde sus raíces en la teoría de la dependencia y el sistema mundo. Hoy por hoy, es insoslayable el hecho de que esta desigualdad global y la división de trabajo configura un campo político en el que ser ciudadano de un pais del tercer mundo no es comparable a serlo del 
primer mundo. Por otra parte, esta concepción de ciudadanía cosmopolita elude incorporar en el análisis el modo en que las dimensiones territoriales e identitarias sigue jugando un papel crucial en la redefinición de los espacios políticos en el campo migratorio transnacional, como hemos demostrado en este trabajo. Ambos aspectos, en su articulación, permiten enmarcar alguno de los procesos etnográficos aquí descritos y dotarlos de cierto grado de generalización más allá de las particularidades concretas del estudio de caso de Jatum Pamba.

Como hemos afirmado antes, el concepto de ciudadanía transnacional adquiere sentido en un espacio político que se crea desde distintos niveles y actores sociopolíticos a través de prácticas políticas de reivindicación de derechos y manifestación de sentimientos de pertenencias políticas que cruzan fronteras y alteran sustancialmente el modelo nacional de soberanía. Se trata por tanto de ir más allá de las prácticas de ciudadanía extraterritorial o nacionalismo desterritorializado para indagar en aquellas prácticas de pertenencia y titularidad de derecho que cruzan fronteras y que se retroalimentan de manera que el ejercicio ciudadano en uno de los polos altere el ejercicio ciudadano en el otro. Por ello, el trabajo ha enfatizado a través del análisis etnográfico la retroalimentación de las prácticas de ciudadanía de los transmigrantes en origen y destino. El modo en que su acceso a la ciudadanía parcial en el mundo rico impacta en origen y cómo su transformación en la pertenencia y titularidad de derechos en origen tiene a su vez efectos en su situación en destino. Desde esta perspectiva la ciudadanía transnacional es un campo social emergente, en que múltiples instituciones y agentes están involucrados, pero que, a fin de cuentas, en un contexto neoliberal se viene a legitimar de maneras novedosas la etnoestratificación y el desequilibrio global que está en la base y es efecto de la movilidad humana.

\section{NOTAS}

1 Mi primer trabajo de investigación sobre el impacto de los procesos migratorios en la transformación del modelo de ciudadanía se remite a una etnografía que se inició en 1992 y terminó en 1996, en Granada y Senegal, cuyo objetivo fue la comprensión de la dramática transformación de España, y en concreto Andalucía, en su posición en los flujos migratorios del Mediterráneo (Suárez 1996, 1998, 2004). Después de otros trabajos dedicados también a la compleja relación entre migración y ciudadanía desde la perspectiva antropológica, como los movimientos de los sin papeles, las transformaciones de las estructuras de género, o la migración de menores como un nuevo sujeto migratorio, inicio una linea de investigación sobre prácticas transnacionales, globalización y ciudadanía, basado en un estudio comparado de senegaleses, rumanos y ecuatorianos en España y sus países de origen, financiado por el Programa Nacional de Investigación I+D del Ministerio de Educación y Ciencia, BS0200203331, y de la Comunidad Autónoma de Madrid, 06/0140/2002. Agradezco a estas entidadades su apoyo, a los estudiantes de doctorado que han aportado ideas en cursos y seminarios, $y$, de manera muy especial, a todos los migrantes que me han ayudado a comprender mejor estos procesos desde su propio punto de vista. Agradezco a Juan Carlos Velasco como editor por sus sugerencias y apoyo para la redacción de este texto.

2 Cf. Collier, Maurer y Suárez 1995, Suárez 1999, Suárez 2005, para un análisis detallado sobre las premisas del modelo de ciudadanía en relación a la aparente dicotomía igualdad-diferencia en relación a los procesos migratorios y las politicas identitarias inscritas en el modelo de ciudadanía.
Aceptado: 18 de junio de 2009 
3 El uso de categorias como migrantes o transmigrantes enfatizan el carácter de doble vinculación de los sujetos estudiados $a$, al menos, dos sociedades políticas y su constante esfuerzo por mantener ambas referencias en sus prácticas cotidianas. Este énfasis es compatible con el uso de categorías como in/e-migrante, siempre que con ellas pretendamos enfocarnos en la posición concreta del migrante en relación al contexto bien de destino o de origen.

4 Para un análisis del concepto de gobernabilidad de la movilidad en el campo migratorio transnacional, cf. Suárez Navaz, 2009 (en prensa).

5 Para una crítica sobre las premisas territoriales que se proyectan en la idea de ciudadanía transnacional, y cuyo efecto es de forma perversa la elusión del análisis de la importancia de la gestión política de la territorialidad y como proyección de las mencionadas premisas epistemológicas, ver Suárez 2007.

6 La dimensión política de las prácticas transnacionales ha generado múltiples estudios que enfatizan una, otra 0 ambas dimensiones de origen/destino; entre otros, son fundamentales los estudios y propuestas teóricas de Bauböck, 2003, Blash et al. 1994, Faist 2000, Fitzgerald 2000, Goldring 1998, Guarnizo et al. 2003, Itzigsohn 2000, Levitt, et al. 2003, Levitt y Glich Schiller 2004, Moctezuma 2005, Østergaard-Nielsen 2003, Portes et al. 2000, Smith 2003, Smith y Bakker 2008, Vertovec 2003.

7 Debo esta observación a Luis E. Guarnizo, quien la presentó en la Universidad Autónoma de Madrid en una conferencia sobre Migración y Desarrollo en 2008.

8 Acabamos de iniciar un nuevo proyecto de investigación $\mathrm{I}+\mathrm{D}$ sobre el fenómeno de los Medios de Comunicación que denominamos de la Diáspora, basados en la importancia que éstos han adquirido como actores sociopolíticos creadores de opinión y de representaciones alternativas a los medios generalistas (CSO200803022, ver www.mecodi.com).

\section{BIBLIOGRAFÍA}

Anderson, B. (1994): "Exodus", en Critical Inquiry, vol. 10 (2), 314-27.

Appadurai, A. (1996): Modernity at Large. Cultural Dimensions of Globalization, Minneapolis: University of Minnesota Press.

- (2004): "Sovereignty Without Territoriality: Notes for a Postnational Geography", en The Anthropology of Space and Place. Locating Culture, S. M. Low y D. Lawrence-Zuñiga, eds., Malden/0xford: Blackwell.

Basch, L.; Glick Schiller, N. y Blanc-Szanton, C., eds. (1994): Nations Unbound: Transnational Projects, Postcolonial Predicaments, and Deterritorialized NationState, Amsterdam: Gordon y Breach.

Baubock, R. (1994): Transnational Citizenship, Aldershot: Edward Elgar.

- $\quad$ (2003): "Towards a Political Theory of Migrant Transnationalism", en International Migration Review, 37.

Beck, U. (2005): La mirada cosmopolita o La guerra es la paz, Barcelona: Paidós.

Benhabib, S. (2005): Los derechos de los otros, Barcelona: Gedisa.

Besserer, J. F. (2004): Topografías transnacionales, Mexico DF: UAM-Iztapalapa.

Bourdieu, P. (1990): Espacio Social y Génesis de las "Clases". Sociología y Cultura, México: Grijalbo.

Calavita, K. (2005): Immigrants at the Margins: Law, Race, and Exclusion in Southern Europe, Cambridge U. P.
Cartillas sobre Migración (2004): "Causas del reciente proceso emigratorio ecuatoriano", n. ${ }^{\circ} 10$, Quito: FEPP.

Castles, S. y Miller, M. J. (2004): La era de la migración [2003³], México: U. Autónoma de Zacatecas / Porrúa.

Collier, J.; Maurer, B. y Suárez-Navaz, L. (1995): "Sanctioned Identities: Legal Construction of Modern Personhood", en Identities. Global Studies in Culture and Power, 2: 1-28.

Faist, T. (2000): The Volumen and Dynamics of International Migration and Transnational Social Spaces, Oxford: Oxford U.P.

Fitzgerald, D. (2000): Negociating ExtraTerritorial Citizenship. Mexican migration and the Transnational Politics of Community, Center for Comparative Immigration Studies, La Jolla, California.

Goldrin, L. (1998): "The Power of Status in Transnational Social Fields", en Transnationalism from below, ed. M. P. Smith, L. E. Guarnizo, New Brunswick y Londres: Transaction Publishers, 130-164.

- (2002): "The Mexican State and Transmigrant Organizations: Negotiating the Boundaries of Membership and Participation", en Latin American Research Review, 37: 55-99.

Guarnizo, L. E. (1998): "The rise of transnational social formations: Mexican an Dominican state responses to transnational migration", en Political Power and Social Theory, 12(12): 45-94.

- (2006): "El Estado y la Migración Global Colombiana", en Migración y Desarrollo, n. ${ }^{\circ}$ 6, 79-101.

Guarnizo, L. E.; Portes, A. y Haller, W. (2003): "Assimilation and Transnationalism: Determinants of Transnational Political Action among Contemporary Migrants", en American Journal of Sociology, 108(6): 1211.

Habermas, J. (1997): "La idea kantiana de paz perpetua: Desde la distancia his- 
tórica de doscientos años", en Isegoría, n. ${ }^{\circ} 16,61-90$.

Herrera, G.; Carrillo, C. y Torres, A. (2005): La Migración ecuatoriana. Transnacionalismo, redes, e identidades, Quito: Flacso-Plan Migración Comunicación y Desarrollo.

Huntington, S. P. (2004): ¿Quiénes somos? Barcelona: Paidós.

Itzigsohn, J. (2000): "Immigration and the boundaries of Citizenship: The Institutions of Immigrants' Political Transnationalism", en International Migration Review, 36: 766-98.

Kant, I. (1998 [1795]): Sobre la paz perpetua; Madrid: Tecnos.

Kymlicka, W. (1996): "Three Forms of Group-Differentiated Citizenship in Canada", en S. Benhabib, ed., Democracy and Difference, Princeton: Princeton U.P., 153-170.

Levitt, P.; DeWind, J. y Vertovec, S. (2003): "International Perspectives on Transnational Migration: An Introduction", en International Migration Review, n. ${ }^{\circ}$ 37.

Levitt, P. y Glick Schiller, N. (2004): "Conceptualizing Simultaneity: A Transnactional Social Field Perspective on Society", en International Migration Review, n. 38(3).

Moctezuma, M. (2005): "Morfología y desarrollo de las asociaciones de migrantes mexicanos en Estados Unidos: un sujeto social y politico extraterritorial", en Migración y Desarrollo, 5.

Ong, A. (1999): Flexible Citizenship: The Cultural Logic of Transnationality, Durham: Duke U.P.

Ostergaard-Nielsen, E. (2003): International Migration and Sending Countries: Perceptios, Policies, and Transnational Relations, NY: Palgrave Macmillan.

Parreñas, R. S. (2005): Children of Global Migration. Transnational Families and Gendered Woes, Stanford: Stanford U.P.
Pedone, C. (2005): "Tú siempre jalas a los tuyos. Cadenas y redes migratorias de las familias ecuatorianas hacia España", en La Migración ecuatoriana. Transnacionalismo, redes, e identidades, ed. G. Herrera, M. C. Carrillo, A. Torres, pp. 105-43, Quito: Flacso-Plan Migración Comunicación y Desarrollo.

Portes, A. (2003): "Teoretical Convergencies and Empirical Evidence in the Study of Inmigrant Transnationalism", en International Migration Review, 37: 874.

Ramírez, F. y Ramírez, J. (2003): La estampida migratoria ecuatoriana, Quito: Centro de Investigaciones Ciudad.

Sassen, S. (1998): Globalization and its Discontents: Essays on the new Mobility of People and Money, Nueva York: New Press.

- (2006): Territory, Authority, Rights. From medieval to Global Assemblages, Princeton: Princeton U.P.

Smith, M. P. (2003): "The Social Construction of Transnational Citizenship", en Journal of International Law and Policy, n. ${ }^{\circ}$, 105-125.

Smith, M. P. y Guarnizo, L. E., eds. (1998): Transnationalism from below, New Brunswick y Londres: Transaction Publishers.

Smith, M. P. y Bakker, M. (2008): Citizenship across Borders. The Political Transnationalism of El Migrante, Ithaca y Londres: Cornell U. P.

Somers, M. R. (1993): "Citizenship and the place of Public Sphere: Law, Community, and Political Culture in the Transition to Democracy", en American Sociological Review, n. 58.

Soysal, Y. (1994): Limits of citizenship. Migrants and postnational membership in Europe, Chicago: The University of Chicago.

Suárez Navaz, L. (1996): "Estrategias de pertenencia y Marcos de exclusión: Colectivos Sociales y Estados en un mundo transnacional", en Procesos migratorios y relaciones interétnicas, ed. A. Kaplan, Zaragoza: IAA-FAAEE, $1-27$.

- (1999): “¿Hacia una ciudadanía postnacional? Fronteras interiores, Integración y Normalización", en Globalización y Fronteras, E. Diaz y J. Pujadas, eds., Santiago de Compostela: FAAEE. (2004): Rebordering the Mediterranean. Borders and Citizenship in Southern Europe, Oxford: Berghahn Books.

- (2006): "Ciudadanía y Migración: ¿un oximoron?", en Revista de Migración, Puntos de Vista, n. ${ }^{\circ}$ 4, 29-47.

- (2007): "Identitat, territori, i ciutadanies en el camp migratori transnacional", en Revista d'Ethnologia de Catalunya, n. ${ }^{\circ} 30$.

- (2008): "La perspectiva transnacional en los estudios migratorios: génesis, derroteros, surcos", en La inmigración en la sociedad española: una radiografía multidisciplinar, J. García Roca y J. Lacomba, eds., Barcelona: Bellaterra, 771-794.

- (2009): "Políticas de Gobernabilidad del campo migratorio transnacional: reflexiones a partir del caso de latinoamericanos en la Unión Europea", en Migraciones Latinoamericanas y Ciudadanía Transnacional, Besserer, F., ed., México: Iztapalapa (en prensa).

Suárez Navaz, L.; Castañón, S. y Anadón, E. (2006): "La mujer indígena ante la migración: Estudio de caso de una comunidad andina", en Anuario Museo Antropología XII, 12-40, Madrid: Museo de Antropología.

Suárez Navaz, L. y Crespo, P. (2007): "Familias en movimiento: el caso de las mujeres rumanas en España", en Migraciones, n. ${ }^{\circ} 21,235-57$.

Suárez Navaz, L.; Macià, R. y Moreno, A., eds. (2007): Movimientos de sin- 
papeles. Hacia una extensión de la ciudadanía, Madrid: Traficantes de Sueños.

Toral, G. (2009): Capital social, legitimidad e integración de las organizaciones de inmigrantes: un análisis tridimensional del caso español (Tesis de Master en Migración, Refugio y Relaciones Intercomunitarias, UAM), manuscrito.

Velasco, J. C. (2007): "Un solo mundo o la perspectiva global de la justicia", en Contrastes. Revista Internacional de Filosofía, vol. XII, 279-288.
Vertovec, S. (2003): "Migrant Transnationalism and Modes of Transformation", en International Migration Review, n. ${ }^{\circ} 38,970-1001$.

Young, I. M. (2000): La justicia y la política de la diferencia, Madrid: Cátedra-Universidad de Valencia. 